\title{
Climate Induced Migration and Social Mobility Among Migrants: Evidence from the Southwest Coastal Region of Bangladesh
}

\author{
Ishita Shahid Sams \\ Institute of Population Research, Peking University, Beijing, China
}

Email address:

ishita.antara@pku.edu.cn

To cite this article:

Ishita Shahid Sams. Climate Induced Migration and Social Mobility Among Migrants: Evidence from the Southwest Coastal Region of Bangladesh. Social Sciences. Vol. 8, No. 4, 2019, pp. 147-159. doi: 10.11648/j.ss.20190804.12

Received: May 20, 2019; Accepted: June 24, 2019; Published: July 10, 2019

\begin{abstract}
Climate induced natural disasters is a common phenomenon of the southwest coastal region in Bangladesh, where rural-urban migration has been considered as an adaptation strategy to survive from the adverse situation of natural disasters. For this type of internal migration, the migrants face multiple hazards, such as occupational change in destination, poverty, gender discrimination, risk of violence, social inequality, social disharmony and conflict with the host community etc. which influence the individual's social mobility that may be upward or downward. This qualitative research explores the social mobility of the climate migrants to assess the migrants' socioeconomic as well as occupational changes. For this study, we have collected the data from the cyclone Sidr and cyclone Aila affected migrants who were migrated internally from the disaster-prone southwest coastal region to the neighboring divisional city Khulna of Bangladesh. After analyzing the primary data, the results have been shown that most of the climate migrants were changed their occupations due to the failure of deriving a secure income in destination places. According to the present socio-demographic profiles and the social status of the climate migrants, poor housing conditions, food insecurity, gender discrimination and structural inequalities in access to properties and control over resources, lack of access to urban culture and identity crisis related with social prestige are created the social disharmony in the society. Most of the rural middle class migrants are shifted in lower class in the context of urban life which indicate downward social mobility caused by climate induced unsuccessful migration.
\end{abstract}

Keywords: Climate Change, Natural Disaster, Migration, Social Mobility, Bangladesh

\section{Introduction}

Frequent natural disasters are the inescapable threats to the people of Bangladesh due where migration is a common livelihood strategy in response to the loss of climate-sensitive occupations and low adaptive capacity. In 2018, according to the report of World Bank, without concrete development action, 143 million people of Sub-Saharan Africa, South Asia, and Latin America would be migrated internally in their countries to escape the slow-onset impacts of climate change by 2050 , where 13.3 million would be Bangladeshi people [1]. Considering the long-term impacts of extreme weather events, Germanwatch reported that Bangladesh has been ranked sixth among the most adversely affected countries by the extreme weather events during the period of 1997-2016 [2]. The risk of floods and loss of lives and properties is highest in Bangladesh by the fifth assessment report of the Intergovernmental Panel on Climate Change [3]. From 1877 to 2009, 159 cyclones, including 48 severe cyclonic storms, 43 cyclonic storms and 68 tropical depressions struck in Bangladesh [4]. In coastal region of Bangladesh, rising sea levels, salinity, extreme floods, storm surge, tropical cyclone, river bank erosion etc. are the common climatic events resulting wide spread damage to infrastructure, livelihoods, properties and settlements in the last three decades [5]. Evidence from Bangladesh Bureau of Statistics (BBS), the coastal zone of Bangladesh has nineteen southern districts which compromise 2.85 million hectares in the area, $200 \mathrm{~km}$ in length including 148,000 square $\mathrm{km}$. of crisscrossed rivers [6]. These districts are characterized by a high pace of population growth and which pushing millions of people living in the low-lying remote islands [7]. Among 
the other parts of Bangladesh, three southwest coastal districts namely Bagerhat, Khulna and Satkhira are more disaster-prone areas because of its ecological and environmental conditions. Four severe cyclones namely, Sidr, Nargis, Bijli and Aila hit the southwest coastal regions and affected those districts massively from 2007 to 2009 [8]. After cyclone Sidr and cyclone Aila, a large number of people had been displaced owing to those cyclones from southwest coastal regions of Bangladesh [9]. The most destructive cyclone Sidr hit on November 15, 2007 in these areas that considered super cyclone resulting 650,000 people were displaced from those areas [5]. Such type of migration posed a serious threat towards social stability and leaded towards social conflict [10]. The last destructive cyclone Aila struck the southwest coastal area of Bangladesh on May 25, 2009 which considered as a category one cyclone. For the sudden onset effects of that cyclone, 2.3 million people were displaced from their origin [11]. In 2017, Environmental Justice Foundation predicted that one in every seven people in Bangladesh will be displaced by climate change where more than 18 million people may have to move because of sea level rise alone by 2050 [12].

In 2016, Stojanov et al. revealed that the local experts of Bangladesh considered the migration as an adaptation strategy to the climate change [13]. However, the relationship between the climate induced natural disaster and migration is often complicated because migration is a multi-causal phenomenon which is usually related to social and economic resources, access to information, political and cultural factors [14-15]. The people try to survive with the adverse situation in different ways where permanent or temporary migration is the important adaptation strategy for the disaster-prone community [16-17]. The people of those affected areas in Bangladesh lose their livelihoods, homes, shrimp farms, farmland and livestock suffer from the shortage of adequate food, drinking water, medical care [18]. After natural calamities, sometimes people are uprooted from their origins and they lose their occupational resources and equipment, resulting they are forced to move under distress situation to escape the long-term impacts of climate change. They try to find a new job and most often, they are forced to change their occupations for their survival in the destination. The migrants get new identity in their destination for their occupational change as well as socioeconomic changes, which can measure by the social mobility. The impacts of climate induced natural disasters are probable to affect population distribution and the social mobility [19].

Many research works related to climate induced ruralurban migration mainly focused on the causes of migration and livelihood changes of the migrants. However, there is no perspicuous statement about the changes of the socioeconomic status of the climate migrants after permanent rural-urban migration. In 2014, Ahsan examined the drivers of migration with the impacts on the livelihoods of the explosion of climate migrants in Bangladesh. The migrated people had no alternative choice but to migration to the adjacent cities of the country as their homes and lands were destroyed [20]. Sultana and Mallick discussed the adaptation strategies after cyclone in southwest coastal region where migration was one of the adaptation process for natural disasters [17]. They reported that income constraints prompted the families decided to migrate to the nearest city Khulna. In 2016, Ahmed et al. described the community resilience to climate induced disaster in the coastal region of Bangladesh [21]. Mallick, et al., narrated the south-western coastal peoples' livelihood vulnerability with the risks of cyclone in this disaster-prone area of Bangladesh in 2017. In their study, they reported that a significant number of poor people were primarily migrated to the urban areas for securing their livelihoods as well as maintaining their families. Moreover, the authors stated that the decision of migration was a coping mechanism in response to the worse effects of cyclone disasters [22].

Indeed, almost all the existing scholarly articles were revealed that the migration was an adaptation strategy for the aftermath of climate induced natural disasters which pushed the affected people to displace from their origin. However, they overlooked the migrants' socioeconomic transformations: change of occupation, social class and status in the destination, could be measured by social mobility among the migrants. In fact, successful or unsuccessful migration probably depends on upward or downward social mobility. We can clearly specify the climate migrants' livelihood changing trend and socioeconomic change by measuring the individual's upward or downward social mobility. The individual's upward or downward position in the society is measured by social class, occupation, education, skill, gender etc., which influence the social mobility [23]. If climate induced migration is less successful then it will create multiple hazards for the migrants' livelihood and the host community as well as the society. Actually, migration due to frequent natural disasters is a continuous process and it can create multi-dimensional variability: accommodation problems, poverty, gender discrimination, occupational change, conflict with local community, just a name of few, which all are the parts of the social mobility. That's why, it is necessary to measure the social mobility among the migrants for understanding the migrants' livelihood and socioeconomic conditions after migration.

In fact, this study intends to explore the main causes and consequences of migration in the context of the socioeconomic variability associated with social mobility based on the empirical evidence from the disaster-prone southwest coastal region of Bangladesh. We have addressed the following research questions to evaluate the livelihood challenges and socioeconomic changes of the climate migrants by considering the social mobility.

How did climate induce natural disaster influence migration? Why did the migrants choose Khulna city as the new destination? What were the livelihood conditions of the climate migrants before and after migration? What were the socioeconomic changes and challenges in the destination places for the migrants who were moved from the southwest 
coastal region of Bangladesh? We have tried to find out the answers of the questions from the climate migrants who had real-life experiences and perception about the natural disasters. Therefore, this study focuses on the internal ruralurban migration due to natural disasters for the consequence of climate change to understand the migrants' actual livelihood and socioeconomic conditions in the society. We examine the existing evidence with respect to the ways how climate induced natural disasters affect the movement of people and find out the protection gaps which is potentially exist. This study will help the policymakers to develop a fruitful policy for ensuring sustainable development to the climate induced migrants.

This article as follows: In section 2, we review some related articles as the literature review. Research methodology is explained in section 3. Research results and discussions with some specific findings are presented in section 4 and section 5 draws the conclusion with some limitations of this research.

\section{Literature Review}

In this section, we review some literatures which are closely related to climate induced natural disaster and subsequent migration. The environmentally unsafe and vulnerable people try to move the safer places for their livelihood resilience and they choose the urban areas, because urban areas are relatively safer than the rural area. This type of migration frequently occurs in south Asian developing countries like Bangladesh, India, Nepal and Pakistan. We have observed the situation of climate induced migration from these countries by overviewing some scholarly articles. Cyclones, floods, rising sea levels, decrease of water volume in major rivers, loss of biodiversity and coral reefs, draught, average temperature rise and increase in natural disasters are the potential biophysical impacts of climate change which create multiple hazards and decline in crop production in these counties [24-28]. Loss of income generating sources as well as poverty are the main barriers with other socioeconomic problems to climate change adaptation in origin places of Bangladesh and India [29]. Considering the challenges of coping mechanism to natural disasters, migration is a typical and important response strategy for the affected people who lose their livelihoods and properties [30]. Moreover, Bangladesh is an example of how the rural-urban migration has become a common adaptation strategy as climate induced natural disasters impacts [15]. In 2014, Mallick narrated the relationship between natural disasters and migration with resulting the social changes of coastal region in Bangladesh. The author tried to focus on the individual household's adaptation strategies in the aftermath of cyclone Sidr and cyclone Aila where the low income group of peoples were migrated primarily towards neighboring cities for searching of better economic opportunities after the ending of emergency relief works. The cyclone disaster affected families took the decision of migration from their origin places to urban areas as the push factors [24].

Economic Survey of India (2016-17) reported that farmers who were more vulnerable to extremes climate changes were more likely to migrate permanently due to continuous loss of assets, land, wealth and livelihood in India. The farmers decided to migrate to the urban for overcoming the risk of loss of income and wanted to avoid social deprivation [31]. However, after migration, most of the migrant workers did not have access to any kind of social protection schemes and they failed to draw the full benefits as they were 'migrants' and not 'citizens' of the city [32]. Lack of access to resources and power created the vulnerabilities for the migrant workers. Their vulnerabilities extended the equity gap for the processes and structures of unplanned rapid urbanisation, environmental change and social marginalization [33]. In 2016, Neupane et al., described the climate induced ruralurban migration in India which leads to a set of socioeconomic, political and environmental challenges for urban areas. They tried to know how that migration challenged the urban planning and development in India. Climate migrants who were poor and unskilled, mainly had to work as unskilled laborers in the construction, transportation, industrial and other sectors. Social inclusion was the biggest challenge for the migrant workers in India [25]. There was no governmental monitoring for the affected people after migration in the destination places in India due to the lack of actual data about climate migrants. Similar with India, in Bangladesh climate induced migrants are not recognized as a category of population in the national or city level policies [24-25]. However, the national policies of Bangladesh concern about the climate change and environmental issues such as Bangladesh Climate Change Strategy and Action Plan 2009, the Climate Change Cell, 2009 and National Plan for Disaster Management (NPDM) 2016-2020 [34-36]. But there are no clear instructions in these policies and laws how the displacement problems will be addressed. In addition, for many countries of the world about internal migration owing to environmental calamities, especially in developing countries like Bangladesh where climate induced migration are not included in the national census [9]. Same situation can be seen in other countries of South Asia such as Nepal and Pakistan.

In Nepal, Gautam examined the climate migrant's livelihood resilience in 2017. The author stated that over the last few decades the total rainfall in both summer and winter decreased which badly affected farmers' crop production and created the food insecurity at Humla in Nepal. For that reason, the farmers decided to migrate from rural to urban seasonally which followed in off-farm opportunities during the agricultural lean season. The migrated people tried to earn money from the cities for upgrading their economic condition. Most of the migrants had to work low paying jobs so that some migrants were actually left with no money when they returned home. Such type of seasonal migration unable to contribute significantly to livelihood resilience in the face of environmental changes for poor social networks, limited education, and lack of the financial capital [27]. The author 
mainly described the farmers' migration where men were only migrated to fulfil the food insecurity to overlook other occupational groups which was the main limitation of that article.

Rapid climate change triggered and aggravated disasters in Pakistan that forced people to escape their homes. In 2016, below-average rainfall resulted in drought and lower crop production in this country which forced hunger-stricken people to migrate to other areas for food. Due to sea level rise, coastal floods and rainfalls many people migrated from near the Indus delta area in Pakistan. Those natural calamities affected agriculture and business sectors in Pakistan. Farmers and other people migrated from rural to urban areas. The government did not take the necessary initiatives to deal with the migrants' socioeconomic and health problems [37]. In 2016, Saeed et al., described that the agricultural productivity in rural areas of Pakistan was affected by differences in climate variables such as average temperature and precipitation and heat stress. Also drought was another important climate phenomenon that significantly impacted the crop harvests of wheat, rice, cotton and sugar cane. Decline in crop production negatively impacted on the farmers and that situation was influenced them to move towards urban settlements for seeking alternative livelihoods. In Pakistan, rural-urban migration increases urban population and the high growth of urbanization has raised concerns about the capacity of the urban systems [28]. The authors highlighted the climate induced rural-urban migration as the social problem in the urban society but ignored to measure the changing trends of socioeconomic position and social class among the migrants.

It is clear from the above literatures that, the natural disasters induced human displacement is one of the major socioeconomic problems in the disaster-prone areas of the south Asian countries. Almost all articles related with climate induced migration mentioned that internal migration was an adaptation strategy for the climate migrants. The literatures narrated the causes of migration, crisis of surviving in new life of the destination places, and the socioeconomic change of migrants. However, these related articles fail to explain the changing trends of social status, conflict with host community, social discrimination and inequality with other problems, which are important tools for measuring social mobility of the migrants. Considering the gaps of the scholarly articles, this research is quite different from other research works. Thus we attempt to show the qualitative analyses of migration where the study briefly describes the socioeconomic changes of the migrants by comparing the migrants' livelihood both before and after migration. Moreover, we want to show that the climate induced migration from rural to urban provides the new identity of the migrants' in the context of urban life and their socioeconomic change is closely associated with social mobility. We have highlighted these issues in this article which are not clearly identified in previous researches.

\section{Material and Methods}

The study is based on qualitative research by using indepth interviews and focus group discussions (FGDs) for extracting relevant information from the migrants who were affected by climate induced natural disasters such as cyclone, flood associated with riverbank erosion and water logging. Actually, the migrated respondents were affected by the cyclone Sidr or Aila. All but seven respondents were migrated from southwest coastal region, namely, Dacope, Koyra, Paikgacha (sub-districts of Khulna district), Morrelganj, Sarankhola (sub-districts of Bagerhat district), Shyamnagar, and Assasuni (sub-districts of Satkhira district) to Khulna City Corporation (KCC). The people who were migrated from disaster-prone areas, were not identify as climate migrants. There was no official survey or census data of those migrants' people. For that reason, it was incredibly difficult to find out actual number of data about climate migrants who were migrated from southwest coastal areas to Khulna. Primarily the homeless and landless poor migrated people were sheltered in the city slums of Khulna. Therefore, we purposively selected five city slums namely Gollamari, Baghmara, Mujgunni, Labanchhara and Notunbazar of KCC and collected the primary data from those study areas by using purposive sampling technique. We interviewed 30 indepth interviews and five FGDs where exactly 7 respondents were participated for each FGD. Three key informants provided the information about the respondents who were migrated from the southwest coastal areas. Then, we conducted in-depth interviews about 30 climate induced migrants where 20 was males and 10 was females and their age was between 21 years to 60 years. Moreover, they had the practical experience to deal with natural calamities as well as sheltered in city slums of Khulna for the adverse effects of natural disasters. They were cordial in providing information about their life experiences before and after migration.

For in-depth interviews, we collected the data from Gollamari, Baghmara, and Mujgunni slums from the midJanuary 2017 to the end of February 2017 and we conducted FGDs at Labanchara and Notunbazar slums in July 2017. A semi-structured interview guide and a checklist were developed by ourselves to measure the livelihoods of the climate migrants and their social mobility for in-depth interview and FGD respectively. To cross check the reliability of the data, we have selected 10 respondents from 30 in-depth interviews randomly and re-interviewed them in August, 2017. Each in-depth personal interview took at least 40 minutes. The interviews were recorded and later transcribed from Bengali to English. For the FGDs, 18 men and 17 female participants were invited to discuss specific aspects of climate change, migration, occupational change, social inequality, deprivation and conflict with the host community, which are the important elements to measure social mobility. We conducted another FGD on seven host people where four females and three male participants were participated to understand the relation between migrants and 
host people. The migrated participants of FGDs were discussed freely about their experiences before and after migration.

All of the respondents were asked in the general information like name, age, sex, age at migration, religion, home district, place of origin, number of schooling years etc. The demographic characteristics of the respondents such as family size and type, marital status, number of children, etc. and socioeconomic characteristics of the respondents, such as occupation, family income, monthly income and expenditure etc. of the migrants were collected. Beside this, we collected the information about the migrants' household environment, sanitation and source of drinking water, electricity, fuel management, amount of land and properties, social activities, entertainment facility, the initiatives of the government organizations and the nongovernment organizations before and after migration etc. We asked to the respondents about the reasons of migration, reason behind choosing Khulna city as the destination place, socioeconomic changes and challenges in urban life. All questions were made for climate induced migration perspective to acquire the comprehensible ideas about the transform of the migrants' livelihood by measuring social mobility. We directly observed available natural, social and individual resources as well as the socioeconomic condition of the migrants to understand the livelihood change of the study areas. Moreover, it identified the socioeconomic impacts of internal migration on the livelihoods of the local community. The collected data were analyzed and interpreted by ourselves. Secondary information were collected from the relevant research studies and documents, scholarly articles, published books, government and non-government research and policy documents for the better analysis of our data.

\section{Results and Discussions}

People have temporary or permanently migrated for some specific reasons, often with a combination of forced and voluntary reasons to push them away from current situations and to pull them towards new circumstances. In this paper, we have examined the perceptions of migration among the respondents as a climate change adaptation strategy from southwest coastal areas of Bangladesh. All aspects of the migrants were intensively observed which were actually composed by two terms; one was the reality from social aspect and another was economic aspect. In this study, male and female participants were 38 and 27 respectively where the age of the respondents was between 21 years to 60 years. Most of the respondents had less than ten years of schooling and a few respondents had more than ten years of schooling. Most of the respondents had a large family with five to seven members. Total 19 respondents migrated after cyclone Sidr and 39 respondents came to the city slums after cyclone Aila with other climatic hazards such as salinity, riverbank erosion, water logging etc. With regard to employment activities following migration to Khulna city, most male respondents were rickshaw/van-puller, day laborer, ship- breaker and female respondents were basically homemaker and rest of the female were housemaid. A wide gap was found in monthly income of the respondents before and after migration due to cyclone disasters.

The core concentration of the study is to observe the socioeconomic reality of climate induced migrants in Khulna city who live in the city slums. Population structure, density and size as well as disease prevalence all are important demographic variables making a decision for internal migration. Political drivers such as weak political support from government, discrimination, conflict, national policy also influence the people to migrate. Social drivers such as social status and dignity, education, family are also important factors that can determine an individual's ability to migrate and manage a job in the destination place. After migration, respondents' housing condition, income opportunity, occupational change, discrimination, gender inequality, poverty, conflict with host community, urban life advantage and disadvantage etc. are influenced their overall socioeconomic condition. Here we try to understand the changing livelihood trends as well as socioeconomic transformations of the migrants to measure the social mobility of the migrants by the following facts and findings. So that the real position of the climate-induced migrants can be recognized in the society. In the following sub-sections are discussed about the research results such as climate hazards and migration, migrants' livelihood conditions in the destination, the factors affecting of social mobility, occupational change of the migrants, education, knowledge and skill backwardness hinder to upgrade the migrants' position, conflict with the host community with some specific research findings.

\subsection{Climate Hazards and Migration}

In Bangladesh, climatic hazards and environmental degradation have been a significant factor contributing to people's migration decision. Climate-related sudden-onset events or natural hazards such as riverbank erosion, floods or tropical cyclones effect on people's mobility in the southwest coastal region of Bangladesh. In addition, rising sea-level and salt water intrusion as the slow-onset events decrease the crops production slowly and water-logging subsequent effects of soil salinization contributing to decision of outmigration. For nature based agricultural livelihoods face the ecological stress particularly when the soil quality deteriorates and agricultural lands must have to be given up. In this situation, the absence of alternative livelihood options in southwest coastal rural areas, permanent displacement is then the logical and often the last outcome. Many of the people in this southwest coastal area had no choice but to migrate to the adjacent cities of the country as their houses and agricultural lands or fish/carb farm were destroyed due to the cyclone Sidr and Aila. They moved away for the lack of resources and the non-availability of income-generating alternatives. They were also socioeconomically vulnerable because of the high rate of poverty and illiteracy, lack of resources, inadequate employment opportunities, loss of 
income from traditional agriculture-based livelihoods and landlessness [38].

The collected data were presented that the respondents were migrated internally for some specific reasons of climate induced natural disasters. In southwest coastal areas, the poor and underprivileged people, women, elder and children are the most severely affected by climate change impacts. They are basically less able to cope with and respond to natural calamities because of their deprived position. They are socially marginalized, economically poorer and politically unprivileged because of less able to decision-making power individually. After cyclone Sidr and cyclone Aila, the affected people displaced for ensuring their economic and social securities. Most of the respondents reported that their houses were completely destroyed. At that moment, most of the victims sheltered in the cyclone shelters, schools, markets, bridges and road sides. All the respondents faced the measurable conditions for the lack of adequate money, food and clothes. The government organizations (GOs) and the non-government organizations (NGOs) provided the reliefs like as dry food, drinking water and sanitation facilities and medical supports such as medicines, doctors and nursing facilities but those were not sufficient for the affected people at that emergency period. The cyclone centers had scarcity of space, food, pure drinking water with the problems of sanitations. Basically women, children, disable and old persons faced those problems severely. They had to share common bathrooms and toilets, in that circumstances diarrhea, dysentery, typhoid and skin diseases were broken out in epidemic form. One of the respondents described his illness after the attack of cyclone Aila that "In the cyclone center most of the men and women were sick such as diarrhea like me. Government, Red Cross and NGOs supplied saline, medicine and pure drinking water but it was not adequate for us. Moreover, we shared the common bathrooms and toilets which were very dirty. At that moment we decided to go to Khulna city for better treatment because there my younger brother lived in who insisted me to come to Khulna."

After the end of emergency periods, the victim people sold their property, like land, gold, cattle for surviving to their origin. Delay in the repairing and reconstructing of the embankments encouraged the affected people to take the decision of migration after the cyclone. Most of the respondents' homestead, agricultural lands washed away and they lost their nature based occupations which triggered them to take the decision of migration. One of the FGD participants told her miserable conditions after cyclone Sidr that - "Our home and agricultural land destroyed by the severe attack of cyclone Sidr and we sheltered in the school building and stayed there for 9 days. We did not get enough relief from government or local political party because we had no good connection with the political parties. After that we went to Khulna for searching a job for subsistence."

All but six migrated respondents kept poultry or livestock which supported them as an additional income source. However, most of the poultry and cattle washed away due to cyclone Sidr and cyclone Aila. After those natural disasters, there was scarcity of food for poultry and livestock. Therefore, they sold those and they lost their additional income sources. Scarcity of drinking water and foul odor of rotten fish and livestock were other reasons for migration. The primary data showed that the severe losses and damages of properties due to both cyclone Sidr and cyclone Aila had a direct impact on the decision of migration. After the cyclones, insufficient supply of reliefs from GOs and NGOs, delay to take essential steps of the local government, hardship of finding a sustainable livelihood, weak political support were influenced the affected people to move towards nearby city Khulna. For those reasons, they forced to migrate as the environmental refugee. It is clear from this research that lower income groups migrated from the disaster-prone areas to Khulna earlier and tried to settle down their lives in the city slums. Lower middle-class and middle-class were struggling with the adverse situations after the slow-onset effects of cyclone Sidr and cyclone Aila. They did not want to migrate from their origin. Though their shrimp and crab farms washed away by the wave of cyclone Aila, they tried to reconstruct their farms by using the micro credit loans from NGOs and selling their some of assets.

However, salinity of land and water as the slow-onset effect of both cyclones and sea level rise were the main constrain to rebuild their farms. The destruction of shrimp and crab farms due to cyclone Sidr and cyclone Aila was one of the most important push factors of migration for the respondents. Though the respondents lost their occupation, they felt hesitation to work as a day laborer in their villages ignoring their social class as well as social prestige and they failed to derive a secure income from their origin places. Those push factors were unavoidably aggravated by unreliable climatic conditions and increased the encouragements to move especially for rural populations with little or no cultivable land. Petty businessmen, vanpullers and day laborers faced income shortfalls as a consequence of reduced work and business opportunities for the sudden and slow onset effects of the cyclones. GOs and NGOs did not take the sufficient initiatives to reduce the climate vulnerabilities of the victims. Furthermore, the respondents could not able to get the benefit of the social safety net programs of the government of Bangladesh.

The collected data identified some "pull" factors to migrate in Khulna city such as availability of unskilled and semiskilled work and desire to upgrade their economic condition in the destination, available access of transportation to reach out to urban areas, better opportunity of education and easy communication system to contact with the relatives in their villages. Actually, Khulna is one of the biggest industrial cities of the southern part of Bangladesh. Seven respondents mentioned that they had relatives in Khulna city who inspired them to come in the city as well as sheltered them initial stage after the migration. One of the respondents told that "My elder brother was stay in Khulna city and he was a vanpuller. After cyclone Aila, my brother gave me the advice to come here and we came to our brother's house in Khulna city 
and he helped me to get a job as a van-puller. He also helped me to find a house in the city slum."

Therefore, the disaster affected people decided to migrate from their villages to this city for better livelihood. Moreover, the fear of future destructive attack of the natural disasters influences the southwest coastal people to move Khulna city as it is safer place than their origin places. One of the female participants of FGD-3 discussed her bitter experience that- "My five years' girl was washed away by the sudden attack of cyclone Aila and we failed to find her. Then we decided to come in Khulna city. We never go back to our village because we want to save our only one son though we cannot earn enough money for our survival."

\subsection{Migrants' Livelihood Conditions in Destination}

The migrants faced natural disasters and hardships at their point of origins but those hardships did not end when they arrived in Khulna city. One-third respondents told that they had no relatives in Khulna city. At first, they sheltered in Khulna railway station or bus stands. In that situation, they did not know where they would go in the city. Four Aila affected respondents reported that they came to the city in a cloth. All the respondents migrated to minimize the risk of poverty and wanted to maximize their household income for upgrading their socioeconomic position. They expected that they would get better income opportunities in the city. But they failed to find a good job for the lack of adequate knowledge and skills. They came here with a full heart of desire but their vulnerable position made them frustrated. The city slums were the first destination of them because the city slums were the cheaper place for living in the city, which were mostly located in the more vulnerable locations and ecologically risk zones. They suffered multiple aspects of deprivation in the city which created an obstacle for obtaining a decent standard of living.

The city slums of Khulna have inadequate access to pure drinking water and sanitation, insecure land tenure and inadequate waste management, transport and electricity. There is a lack of security and other basic services for the climate induced migrants including housing, health and sanitation facilities because of the gaps in significant policies, development plans and strategies which can create the problems in adaptation process of the climate migrants. The slums are located on lowlands or wetlands as the private or public properties in Khulna city and these slums have severe drainage problems particularly during the rainy season. The private land owners are often unaware about migrants' need for services or reluctant to take necessary initiatives to provide the sufficient services. Most of the families live from hand to mouth in those slums where they are struggling to meet their basic needs. For that reason, they tried to rent a house in the cheaper places of the city slums. The rooms are narrow and most of the rooms have one window with the scarcity of day light. Most of the respondents rent one or two rooms with their younger and little children which creates some problems to maintain the privacy of conjugal life. Most of the female respondents use common kitchens to cook food where, sometimes they make quarrel with each other to maintain the serial. They use fire wood for fuel because fire wood is cheaper than the gas cylinder which creates air pollution. In addition, the fuel cost increases the monthly household expenditure of the migrants. Before migration, they did not expend money for the fuel materials for availability of straw, cow dung, wood in their villages.

Most of the respondents have reported that there are no adequate sanitary latrine facilities in their slums. Thus, human wastes are polluting environment and slum duellers are becoming sick day by day due to bad smell from those latrines. They share the common bathrooms and toilets, because they have no alternative way to use those unhygienic latrines. Female respondents face some problems in the use of those toilets for less privacy. Sometimes the toilets and the bathrooms go under water in the rainy season which creates more difficulties for females, children and older people. One female respondent told that- "Last year my mother-in-law broke her leg to go to the toilet in the rainy season because the toilet was sludge. We spent a lot of money for her treatment in the Khulna General Hospital."

In this circumstance, it is quite impossible to maintain the hygiene of common toilets and bathrooms. The sanitation and toilet facilities are very vulnerable of the migrants which are directly linked with their health status. They are often unaware of the bad effects of unsafe water, use of the unhygienic latrines and improper disposal of the solid wastes. For this reason, they suffer from water borne diseases, diarrhea, dysentery and skin diseases. It has negative impacts on the migrants' health that limits their skill and physical ability and increases the health care costs. Though the medical facility in Khulna city is better than their origin places and they can get better treatments from government hospitals in the city, sometimes the migrants go to homeopath doctors or depend on amulet for their treatments because the treatment cost is cheaper than the allopath treatments. Argument about the treatment cost, one of the male respondents reported that- "For fever, cough or skin diseases of my children I use to go to local homeopath doctor because the treatment cost is cheap."

For mental recreation, usually they cannot spend money. Only one respondent has a television and a cassette player. Family income and expenditure are the important indicators to identify the social class which influences the social mobility. The migrants' housing status, environment of living place, water and sanitation facilities primarily demonstrate the downward socioeconomic status. This study has observed that the nature of expenditure in the origin places and the destination places has a noticeable gap. In their origin place most of the time they did not buy fish, meat, vegetables because they had poultry, vegetable gardens and fish farms, ponds. But in Khulna city, they need to buy everything for their survival which increases their daily expenditure. They have a large family member where most of the family members depend on head of the family's income. Therefore, they cannot save money for the future and cannot increase 
their wealth which prevents them from moving to upper social class.

\subsection{The Factors Affecting of Social Mobility}

It is well known to all that in the social ladder upward or downward social mobility depends on some socioeconomic factors such as migration, occupational changes, individual's skill, education, knowledge, social dignity, power, social inequality, gender discrimination, etc. (Schaefer, 2010). After migration, the climate migrants are considering as separate community from the established community for their lower socioeconomic condition. Before migration they were belong in three socioeconomic classes such as lower class, lower middle class and middle class in the rural socioeconomic context of Bangladesh. But after migration, they are regarded the lower class in the context of urban life for their poor socioeconomic condition. The uncertainty of job opportunity is the main constrain to upgrade their socioeconomic status. In fact, this capitalist society, social class plays a vital role for belonging upward or downward social mobility. Therefore, the poverty, poor housing conditions, food insecurity, mental dissatisfaction, the lack of access to urban culture and quality medical care create the constrain for moving into an upward social class which is adversely linked with the upward social mobility. In the following sub-sub sections, we have described some specific socioeconomic parameters which are influential factors to change the migrants' socioeconomic conditions as well as the social mobility.

\subsubsection{Occupational Change of the Climate Migrants}

Migrants' occupational change brings the changes in their intra-generational social mobility in terms of class membership. Most of the people of southwest coastal region depend on increasingly threatened natural resources for their subsistence but the frequent natural hazards change the ecosystem of these areas. This situation limits the working opportunities of the affected people in this circumstance. In their origin, they wanted to avoid taking the loan from the local NGOs after the natural disasters because they had no capacity to repayment the loan with the interest at that time. Therefore, they took the decision for migration as an adaptation strategy. Nevertheless, after migration, some respondents took loans or credit from their relatives, local money lenders, public banks or NGOs for different purposes. The lack of knowledge and skill as well as the financial inadequacy are the main cause of their backwardness. Those who were permanently migrated from their origin due to severe attack of cyclone Sidr and cyclone Aila, they forced to change their occupations. The collected data shows that the majority of migrants are involved in the informal or the unorganized sectors. Depending on their skills and experiences, they go to places where they can work as rickshaw or van-pullers, construction workers, ship breakers or any kind of day labor. Thus, the displaced men face the hardship to cope with the urban social structure. Most of the cases blue-collar migrants' jobs are not permanent. The competition is intense and the payment is low for the informal works. The lack of employment contracts and social networks make migrants more vulnerable to ensure their labor rights. It creates the difficulties to obtain the wealth for securing their livelihoods. Before migration among 35 male respondents, 10 respondents were engaged in fish/shrimp or crab cultivation, 8 respondents were involved in agricultural production, 4 respondents were fishermen, 4 respondents were day laborers, 3 respondents were van-pullers, 3 respondents were wood and honey collectors and 2 respondents were petty businessmen respectively. The monthly income of the fish and carb cultivators were around $15,000$ to 20,000 BDT (1BDT $=0.012 \mathrm{USD})$ and the farmers who had own lands they earned monthly around 12,000 to 15,000 BDT.

After migration, all but six male respondents changed their occupations. Among 23 female migrants, 12 were become homemaker to housemaid and two worked as seamstress who had the training about tailoring work before migration. They earned monthly around 3000 BDT for reducing their economic vulnerability but those incomes did not help them to upgrade the socioeconomic status because the work as housemaid was considered as a lower class job in the context of the urban society. Rest of the female respondents were homemakers. One female respondent said that- "Aila destroyed our homestead and we had no land. My husband was a fisherman. We sheltered in a cyclone center, but at that moment my two children were very sick for diarrhea and skin disease. The supply of food, water and medicines from government and other organizations were not enough for us. We stayed there 17 days then we went to Khulna city in my relative's house. Now my husband is a rickshaw-puller and I am a housemaid."

Cyclone Aila and cyclone Sidr destroyed shrimp and crab ponds and agricultural lands. After the cyclones, water logging or regular inundation destroyed the means of production of agriculture. The respondents who were dependent on cultivation could not produce crops as long as their agricultural land was under the saline water. The shrimp cultivators who lost their shrimp ponds due to the cyclones, they had no alternative way to repay their losses. One of the participants of FGD-2 said that - "I was migrated from Shyamnagar Upzila in Satkhira after cyclone Sidr. Now, I live in Labanchara slum, Rupsha. I could not grow any kind of crop for the salinity of land and water. It was quite impossible for me to survive there with my six family members, moreover I did not get any rehabilitation and reconstruction supports from GO and NGOs. Therefore, I came to Khulna and worked as a construction labor. After five months of migration, my family members were shifted from Shyamnagar to Khulna. Now my wife works as a housemaid to support our family economically."

The people who were involved in collecting wood and honey from the forest of Sundarbans, changed their occupation. They could not continue their works for massive destruction of the Sundarban due to cyclone Aila. The poor respondents had not enough goods to sell which helped them to overcome the adverse situation after the natural disasters. 
Those natural disasters not only forced the poor or extremely poor households to migrate, but also forced middle-class households to displace. Middle-class people tried to survive in their origin places to sell cattle, crops, radio, mobile phone, gold etc. because the agricultural lands were heavily inundated and shrimp farms were totally washed away by the cyclones. But they could not do any odd job because of their social class as well as social prestige in their villages. In that adverse situation, the natures based people lost their occupations and moved to Khulna city for finding alternative income sources.

The farmers, the fish cultivators, the fishermen and other occupational migrants became day laborers, rickshaw-pullers or van-pullers, ship breakers after migration to Khulna city for the lack of their knowledge and skill. They are mostly involved in informal works without organizational sponsorships which indicates the institutional gap in labor welfare and they are deprived to access available public services independently. After migration in Khulna among 35 male respondents 9 were rickshaw-puller, 6 were van-puller, 9 were day laborer, 6 were construction laborer, 3 were ship breaker, 1 respondent was petty businessman and 1 was a hotel manager. The rickshaw-pullers, van-pullers, ship breakers, construction and day laborers earn monthly around 7,000 to 9,000 BDT, because their job is not permanent and they cannot earn equally for every day, even though they cannot manage a work for regularly. This occupational change provides the new identity for the climate migrants. Only the hotel manager successfully reestablished his life in this city because his educational background was better than the other respondents. He passed higher secondary certificate examination, so he got the job as a stuff of a hotel in Khulna then promoted as a hotel manager. Other respondents' socioeconomic position was growing downward and they were treated as lower class for the context of urban life. In their villages, they had an identity and dignity, some wealth, agricultural lands and permanent homesteads. Moreover, the urban living cost is higher than the villages, so they cannot save money for their future life. Most of the day laborer respondents are struggling to get the jobs because day laborers are surplus than the demand in Khulna city. As a result, the day laborers are forced to work in low wages. The data are shown that after migration the involvement of the people with higher sources of income gradually decrease to low paid income. The migrants lost not only their occupations but also their social dignity, honor and status as well as the social networks after migration. It changed their overall livelihood and broke their mental strength because the occupational changes of the migrants leaded the transformation of downward socioeconomic status of their life.

\subsubsection{Education, Knowledge and Skill Backwardness Hinder to Upgrade the Migrants' Position}

In this study, we found among 65 respondents, 11 respondents did not go to school, 33 respondents did not complete their primary education, 19 respondents did not complete their secondary education and only one respondent passed the secondary school certificate examination and one passed higher secondary certificate examination. In this study, we observed that the respondent who passed the secondary school certificate examination, had small scale business in the village, he did not change his occupation after migration in Khulna. After migration, due to the education, adequate experience and knowledge about that business, his socioeconomic position is better than other migrants who are engaged in blue-collar jobs. Another small scale businessman who changed his occupation as an employee of a hotel who took the benefit from the urban life for his educational qualification and successfully upgraded his social position which referred upward social mobility.

Less educated male and female migrants have less access to do any kind of white-collar work. Therefore, they force to work in informal sectors as a blue-collar worker. They cannot upgrade their socioeconomic position as well as social prestige, which is one of the major key factor to create the barrier for upward social mobility. That is why; they realized the importance of education. However, the educational cost in urban area is much higher than the rural area, for this reason, nine migrants among fifty-eight migrated respondents took the loan from the local NGOs to meet up their children's educational cost. One of the female respondents told in her interview that- "My husband was a wood worker but his right leg was injured while chopping wood. After AILA, we migrated from our village to Khulna. As my husband is a disable person, I am the only earning member in our family. I am a housemaid and there is no alternative way to take loans from NGOs to continue my daughter's study in the school, who will sit for SSC examination in 2018."

From FGD-3, one AILA affected male participant informed that- "I did not have any formal education so I did not manage any formal job after migration in Khulna. In my village, I was a farmer but in here, I maintain my large family by working as a construction laborer. After migration, I realized that without higher education it is quite impossible to get a sophisticated job and to upgrade the social position. So I tried to educate my sons. My elder son had already completed his graduation and works as an employee in a cement factory. Another two sons are read in the college. Now my elder son is financially contributing in our family."

The migrants hope that in future their children will be highly educated and will work in the formal sectors as well as reestablish their lives in the city. It would play a vital role to upgrade their social position and promote in intergenerational social mobility. On the other hand, two female respondents had vocational training about tailoring, therefore, they managed some money from NGOs and bought the tailoring machine and started their job as the seamstress after migration in Khulna. Their socioeconomic position is relatively better than other female respondents. Moreover, after migration, the migrants did not get any kind of vocational training from the government organizations or NGOs because they were not recognized as more vulnerable groups in the urban society. The lack of skills and training as 
well as Illiteracy push both male and female migrants to take up mostly manual, unskilled jobs in the labor economy. Therefore, it can be said that educational qualification, vocational training and skill make the difference among the migrants to upgrade their socioeconomic position as well as social mobility.

\subsubsection{Conflict with the Host Community}

Although the city slums have scarcity of lands and other living facilities, male and female migrants settle down in city slums primarily and there may be a risk of violent clash with the host communities. Because the competition increases for using common property resources such as land, water, even though common bathrooms, toilets and kitchens in city slums between the migrants and the local people. Resource scarcity in these areas can help to generate a strong feeling of 'nativism' among the local people in the city. For this reason, hosts fear the destruction of their socioeconomic and cultural harmony by the migrants. This situation may increase the risk of conflict between migrants and host communities. Conflict such as quarrel, clash even though fight in the slums is a regular phenomenon. This situation creates the noise and the violence which disturbs the city dwellers, particularly the nearby residents. This type of social conflict refers to the various types of negative social interaction among the inhabitants of the city slums. These violent clashes between the migrants and the local people in the destination places threat the respondents' livelihood. One of the participants of FGD-3 narrated his miserable condition to manage a work that-

"After migrating to Khulna, I wanted the help from the local workers to find a job, but no one was interested in helping me because it could reduce the earning opportunities."

On the other hand, one of the participants of FGD-5 who was local inhabitant argued that-

"The migrated people create many type of the problems, they make quarrel with us to maintain the serial for using common kitchen or toilets. The migrants provide their labor at cheaper rates, so we are forced to work at cheap rates and they are competing with us for getting the daily work. This situation creates the disharmony among us."

The conflict can be arising when the institutional capacity of the adaptation is weak and the migrants cannot adjust with the local settings due to the unequal access to resources. Migrants' lack of knowledge, skill and capital and discriminatory resource capture between powerful and less powerful groups cause poverty. In this way, poverty and power less position of the respondents create the obstacle to move in the upper social class that influences the downward social mobility.

In addition, temporary exclusion from the local labour market affects the male migrants in a long run and they suffer from identity crises in the urban society. This situation incises the chance of conflict between the migrants and the local people. Beside this, the patriarchal ideology puts the female migrants in an adverse situation with the inferior complexity and sometimes such type of ideology influences men to violent activities against women which creates the problem in the conjugal life as well as the family life. Consequently, women migrants' position is more vulnerable than male migrants for adaptation process in the urban life. Both male and female respondents face the difficulties in getting voter identity cards, political support and other urban facilities because the host people deny to recognize them as the residents of this city.

\subsection{Research Findings}

People had internally migrated for many reasons, often with a combination of forced and voluntary reasons which pushed them away from their origin and pulled them towards new circumstances. In our research, we found the key drivers of migration: (a) factors related to the origin place, including the lack of economic opportunities, the lack of access to resources, scarcity of food, fail to repay old credit, insufficient supply of reliefs from GO and NGOs, delay to take essential steps of the local government, the hardship of finding a sustainable livelihood, weak political support from the local government, delay in the repairing and reconstructing of the embankments, the lack of medical support from the governments in the emergency period after cyclone Sidr and cyclone Aila, destroy of home stead, agricultural land and fish farmland, salinity of water and land, scarcity of drinking water, foul odor of rotten fish and livestock, less able to get the benefit of the social safety net programs of GO, fear of future attack of natural disasters ('push' factors); (b) factors related to the destination place of Khulna city, including the availability of employment and demand for workers, well transportation and communication system or social networks, opportunity to higher education for the children, hope for better economic opportunities and more socioeconomic stability ('pull' factors). Actually, migration represented as an adaptation process to natural hazards due to climate change or uncertainty and it was happened when other options were failed to secure the livelihood of the affected people. After migration, it was quite difficult for the migrants to find a job or a secured shelter without the help of relatives who lived in the same city or the personal networks. Therefore, searching a permanent or temporary job in the destination was the first obstacle for the climate migrants. The unskilled and less educated male migrants mainly involved the informal jobs such as rickshaw pulling or van pulling, ship breaking, daily labor, construction labor and the female migrants were mostly housemaid. Most of the migrants had no permanent jobs, for that reason their monthly incomes were not fixed. Thus migrants' economic activities were mainly related to the unofficial jobs which played an important role to decrease their socioeconomic position and interrupted migrants' intergenerational upward social mobility. Poverty and discrimination in the destination hindered migrants' development of livelihood. Therefore, they could not reorganize themselves for regaining the social class as well as the social prestige. Despite the better educational opportunities in the city, they could not properly educate their 
children due to their poverty. That situation also created the barrier of intergenerational upward social mobility. Besides, owing to the lack of health consciousness and wealth, migrants could not avail the better healthcare services in the city. Poor housing conditions, food insecurity and the structural inequalities in access to properties and control over resources, the lack of access to urban culture created the difficulty to move in upper social class for the migrants.

Additionally, the women migrants' position was more vulnerable than the male migrants because of the discriminatory structure of patriarchal society in Bangladesh. Most of the female respondents were poor, less educated, weak health condition and they had less access to natural resources or ownership of the assets compared to the male respondents. Urban settlement as an adaptation process was not uniform across women and men. Women's adaptation processes were severely challenged by gender relationships which fully originated by the power structure of both within the household level as well as the community level in the patriarchal society. Most of the cases, the host community did not welcome the male and the female migrants for the probability of reducing the job opportunities and declining wages of the local people. That situation increased the risk of violence and conflict between the migrants and the host communities which had a negative impact on the society. Most of the migrated people failed to establish their live successfully in the destination which indicated the downward social mobility. Moreover, the study found that GO and NGOs failed to play the significant role for the overall development of the climate induced migrants due to dearth of adequate monitoring, accountabilities and responsibilities. In fact, the migrants' vulnerabilities in the destination places not only depend on the migrants' skill, knowledge, education and socioeconomic as well as gender position but also the current policies of the government about the climate induced natural disaster managements.

\section{Conclusion}

This study has explored the causes and the consequences of rural-urban migration as well as the social mobility among the migrants owing to natural disasters from southwest coastal areas of Bangladesh. This type of permanent migration is not only environmentally deterministic but also other social, economic and political factors contribute to the decision of migration. Poverty, food insecurity, loss of wealth, destroy and damage of homestead, land and fish farm, the lack of social protection, insufficient financial and social capital as well as the inadequate natural resources are triggered the southwest coastal people to migrate the neighboring city for securing their livelihoods. However, most of the migrated people fail to settle down properly in the destination places for the lack of adequate knowledge and skill. They are unsuccessful to take the advantages of the urban life because of their poverty and vulnerable position in the society. Climate change induced migration crucially impacts the migrants' income opportunities which change their normal way of life and put them in a marginalized position in the society. Therefore, this research has identified the negative impacts of migration decision on the destination places and the socioeconomic transformation of the migrants' livelihood which refers downward social mobility. Proper disaster management knowledge and consciousness, sufficient resources, essential governmental plan and policies can tackle the devastations of natural disasters and protect the coastal people of Bangladesh from the massive destruction of natural hazards and it may reduce the flow of the temporary and the permanent migration from the affected areas. It is quite challenging to achieve the sustainable development goals (SDGs) for Bangladesh without improving the livelihood of these coastal communities. This study focuses the internal rural-urban migration due to the natural disasters with the context of social mobility, so that the government and the policymakers can understand the acute socioeconomic conditions of the migrants and they can make the fruitful policies to develop the migrants' overall situation. Though the government of Bangladesh has established the Climate Change Cell to manage the pre and post natural disaster activities but it is quite difficult task to take the necessary initiatives for the government of Bangladesh alone for protecting the vulnerable coastal people. That's why; national and international collaboration and cooperation are essential to mitigate the challenges against the climate induced natural disasters by reducing poverty and social inequalities for the sake of overall development.

\section{Limitations}

It is important to point out that this social research is based on the empirical survey of in-depth interviews and FGDs in a unique context. However, we could not collect holistic information about the climate induced migration because tracking migrants from a particular natural disaster event was incredibly difficult. Also the National Census of Bangladesh was not included the information about the internal ruralurban climate migration. The lack of adequate data on climate induced internal migration hinders monitoring of rural-urban migration flows, which presents a challenge for decision-making to the policymakers. If we could collect more data on the climate migrants from the southwest coastal area, then the research results would be more applicable in broader aspect.

\section{Acknowledgements}

The author acknowledges to Dr. Hu Yukun, Associate Professor, Institute of Population Research, Peking University, for her guidance, supervision and revising the paper. She is also very thankful to Dr. Lasker Ershad Ali, Associate Professor, Mathematics Discipline, Khulna University, Bangladesh who helped to collect the primary data. 


\section{References}

[1] Riguad, K. K., Sherbinin, A. de., Jones, B., Bergmann, J., Clement, V., Ober, K., Schewe, J., Adamo, S., McCusker, B., Heuser, S. and Midgley, A. (2018). Groundswell: Preparing for Internal Climate Migration. Washington, DC: The World Bank.

[2] Germanwatch. Global Climate Risk Index 2018. Who suffers Most from Extreme Weather Events? Weather related loss events in 2016 and 1997 to 2016. Harmeling, Sven and Eckstein, David. Briefing paper. Bonn, Germanwatch, 2017. www.germanwatch.org/en/cri.

[3] IPCC. Climate Change 2014: Impact, Adaptation, and Vulnerability. Contribution of Working Group II to the Fifth Assessment Report of the Intergovernmental Panel on Climate Change (IPCC), 2014.

[4] Mallick, B. and Vogt, J. (2012). Cyclone, Coastal Society and Migration. International Development Planning Review, 34, 217-240.

[5] EM-DAT. Percentage of People Affected by Disaster in Bangladesh from 1981 to 2016. International Database for Disasters, Louvain, Université Catholique de Louvain, (2016).

[6] BBS. Bangladesh-population-and-housing-census-2011, Bangladesh, Bureau of Statistics (BBS), 2011.

[7] World Bank. The World Bank Annual Report 2012. Washington, DC, 2012.

[8] Akhter, M. N., Chakraborty, T. K., Ghosh, G. C., Ghosh, P., and Jahan, S. (2012). Migration Due to Climate Change from the South-West Coastal Region of Bangladesh: A Case Study on Shymnagor Upazilla, Satkhira District. American Journal of Environmental Protection, 5 (6), 145-151.

[9] IOM-2009. Migration, Environment and Climate Change: Assessing the Evidence. International Organization for Migration (IOM), Geneva, Switzerland, 2009.

[10] IOM-2008. Migration and Climate Change. Prepared for IOM by Oli Brown. IOM Migration Research Series. Research paper no. 31. International Organization for Migration. Geneva, 2008.

[11] IDMC. Displacement due to natural hazard-induced disasters Global estimates for 2009 and 2010 Internal Displacement Monitoring Center (IDMC), June 2011.

[12] Environmental Justice Foundation. Country Master, United Nations Department of Economic and Social Affairs: Population Division, 2017.

[13] Stojanov, R., Kelman, I., Ullah, A. K. M. A., Duzi, B., Prochazka, D. and Blahutova, K. K. (2016). Local Expert Perceptions of Migration as a Climate Change Adaptation in Bangladesh. Sustainability, 8, 1223-1237.

[14] Chanda, S. K. (2010). Effect of Cyclone AILA: Migration Tendency of the Resident. Journal of Socioeconomic Research \& Development, 7 (6), 975-980.

[15] Black, R., Kniveton, D. and Schmidt-Verkerk, K. (2011). Migration and Climate Change: Towards an Integrated Assessment of Sensitivity. Environment and Planning A, 43, 431-450.

[16] Mallick, B., Rahaman, K. R. and Vogt, J. (2011). Coastal
Livelihood and Physical Infrastructure in Bangladesh after Cyclone AILA. Migration and Adaptation Strategies for Global Change, 16, 629-648.

[17] Sultana, Z., and Mallick, B. (2015), Adaptation Strategies after Cyclone in Southwest Coastal Bangladesh-Pro Poor Policy Choices. American Journal of Rural Development, 3 (2), 24-33.

[18] Rahman, M. A., Hossain, M. L., Foysal, M. A. and Akter, A. (2014). Impact of Climate Change on Food Security in SouthWest Coastal Region of Bangladesh. American Journal of Experimental Agriculture, 4 (12), 1916-1934.

[19] Tacoli, C. (2009). Crisis or adaptation? Migration and climate change in a context of high mobility. Environment and Urbanization, 21 (2), 513-525.

[20] Ahsan, R. (2014). Climate Induced Migration: Lessons from Bangladesh. International Journal of Climate Change: Impact and Responses, 5, 1-14.

[21] Ahmed, B., Kelman, I., Fehr, H. K. and Saha, M. (2016). Community Resilience to Cyclone Disasters in Coastal Bangladesh. Sustainability, 8, 805-933.

[22] Mallick, B., Ahmed, B., and Vogt, J. (2017). Living with the Risks of Cyclone Disasters in the South-Western Coastal Region of Bangladesh. Environments, 4 (1), 13-29.

[23] Schaefer, R. T. Sociology Matters (5th ed.). New York, NY: McGraw-Hill van Laar, 2014.

[24] Mallick, B. (2014). Cyclone-induced Migration in Southwest Coastal Bangladesh. Disasters, 38, 654-671.

[25] Neupane, K. W., Rubinyi, L., Sivappha, T. and Wang, Y. (2016). Climate Migrants and Urban Adaptation in India and China Prepared for University of Notre Dame Global Adaptation Index (ND-GAIN) By Workshop in International Public Affairs Spring 2016.

[26] Bhatta, G. D. and Aggarwal, P. K. (2016). Coping with weather adversity and adaptation to climatic variability: a cross-country study of small holder farmers in South Asia. Climate and Development, 8 (2), 145-157.

[27] Gautam, Y. (2017). Seasonal Migration and Livelihood Resilience in the Face of Climate Change in Nepal. Mountain Research and Development 2017, 37 (4), 436-445.

[28] Saeed, F., Salik, K. M. and Ishfaq, S. (2016). Climate Induced Rural-to Urban Migration in Pakistan. ODI Working Paper, $2016 . \quad$ http://prise.odi.org/wpcontent /uploads/2016/01/LowRes-Climate-induced-rural-to-urbanmigration-in-Pakistan.pdf.

[29] Eisenack, K. Archetypes of adaptation to climate change. In Human/Nature Interactions in the Anthropocene: Potentials of Social-Ecological Systems Analysis; Glaser, M., Krause, G., Ratter, B., Welp, M., Eds.; Ökom Verlag: Munich, Germany, 2009.

[30] Islam, M. D. M., Sallu, S., Hubacek, K. and Paavola, J. (2014). Migrating to tackle climate variability and change? Insights from coastal fishing communities in Bangladesh. Climate Change, 124, 733-746.

[31] Government of India. The Economic Survey 2016-2017. https://www.thehinducentre.com/multimedia/archive/03193/E conomic_Survey_20_3193543a.pdf. 
[32] Jha, C. K., Gupta, V., Chattopadhyay, U. and Sreeraman, B. A. (2018). Migration as adaptation strategy to cope with climate change: A study of farmers' migration in rural India. International Journal of Climate Change Strategies and Management, 10 (1), 121-141.

[33] Bhagat R. B. (2014). Climate Change Vulnerability and Migration in India: Overlapping of Hot Spots. National Workshop on Migration and Global Environmental Change in India, March 2014.

[34] Ministry of Environment and Forests (MoEF). Bangladesh Climate Change Strategy and Action Plan (BCCSAP) 2009; Ministry of Environment and Forests, Government of the People's Republic of Bangladesh: Dhaka, Bangladesh, 2009.

[35] CCC-2009. Characterizing Country Settings: Development of a Base Document in the Backdrop of Climate Change Impacts, Climate Change Cell (CCC), DoE, MoEF, Component 4b, CDMP, MoFDM. GoB, 2009.

[36] Government of the People's Republic of Bangladesh, Ministry of Disaster Management and Relief (National Plan for Disaster Management 2016-2020).

[37] Ijaz, A. (2017). Climate change and Migration in Pakistan. https://thediplomat.com/2017/08/climate change and migration -in-Pakistan/.

[38] Sams, I. S. (2019). Impacts of Climate Change Induced Migration on Gender: A Qualitative Study from the Southwest Coastal Region of Bangladesh. International Journal of Social Science Studies, 7 (4), 57-68. 